\title{
Foreign Accent Syndrome in a Patient with Multiple Sclerosis
}

\author{
Jacqueline I Bakker, Suzanne Apeldoorn, Luanne M Metz.
}

\begin{abstract}
Background: Foreign accent syndrome is a speech disorder which leads listeners to perceive the patient as having a foreign accent. It has been recognized previously after stroke, brain injury or unknown causes. Case report: A 52-year-old woman with clinically definite relapsing remitting multiple sclerosis (MS) presented with episodes of what was perceived as a Dutch accent along with other neurologic symptoms that would resolve simultaneously. She was assessed by a speech therapist both during an episode and after complete recovery. Speech and MRI changes (showing deep white matter lesions in the corpus callosum, left pariental lobe and left frontal lobe) were consistent with previous reports of foreign accent syndrome. Conclusions: This patient's episodes of foreign accent are thought to be due to her MS. This is the first case reported of a patient with foreign accent syndrome secondary to MS.
\end{abstract}

RÉSUMÉ: Syndrome de "l'accent étranger" chez une patiente atteinte de sclérose en plaques. Introduction: Le syndrome de l'accent étranger est un trouble du langage dans lequel le patient est perçu par l'entourage comme ayant un accent étranger. Cet état a déjà été observé après un accident vasculaire cérébral, un traumatisme cérébral ou sans cause connue. Observation: Une femme âgée de 52 ans, atteinte de la forme rémittente de sclérose en plaques (SEP) confirmée, a consulté pour un phénomène épisodique comprenant un trouble du langage, perçu par l'entourage comme un accent hollandais associé à d'autres symptômes neurologiques qui disparaissaient simultanément. Elle a été évaluée par un orthophoniste pendant un de ces épisodes et après résolution complète du phénomène. Le trouble du langage et les changements observés à l'imagerie par résonance magnétique, qui montrait des lésions profondes de la substance blanche dans le corps calleux, le lobe pariétal gauche et le lobe frontal gauche, concordaient avec ceux rapportés antérieurement dans le syndrome de l'accent étranger. Conclusions: Nous attribuons ce phénomène épisodique à la SEP chez notre patiente. Il s'agit du premier cas rapporté de syndrome de l'accent étranger secondaire à la SEP.

Can. J. Neurol. Sci. 2004; 31: 271-272

Foreign accent syndrome was described as early as $1918 .{ }^{1}$ It is defined as a speech output disorder occurring subsequent to a brain lesion causing aberrations in pitch, inflection, stress and articulation; it leads listeners to think that the patient has a foreign accent. ${ }^{2-5}$ Previously reported cases were secondary to stroke, traumatic brain injury, or unknown causes. ${ }^{2-10}$ We report a woman with multiple sclerosis (MS) who developed transient episodes of foreign accent syndrome which we believe are related to her MS. This is the first reported case of foreign accent syndrome secondary to MS of which we are aware.

\section{CASE Report}

This 52-year-old left handed woman presented with abnormal speech. She had a 20 year history of relapsing remitting MS. Her main MS symptoms included moderate ataxia, fatigue, Uhthoff's phenomenon and neurogenic bladder. Her past medical history included hypertension, asthma and two previously excised melanomas.

Her symptoms at presentation included decreased memory, word finding problems, grammatical errors and labile emotions. There was no dysphasia or dysarthria but she had what sounded to be a European accent. Our patient speaks only English with a Canadian accent as do her parents and grandparents. When compared to a voice message on her answering machine recorded months earlier there was an obvious change in her speech. She reported four previous episodes of speech change over the last five years. Others thought she had a Dutch accent. These episodes lasted four to six weeks and worsened with fatigue. They were always associated with other neurologic symptoms; all symptoms resolved simultaneously. Twelve to 24 hours prior to each episode her speech became slurred and scanning, her tongue felt thick and her jaw felt tight. Previous treatment with decadron had not been helpful.

Neurologic examination showed: pale optic discs bilaterally, right

From the Department of Clinical Neurosciences, University of Calgary (JIB LMM), and Calgary Health Region (SA), Calgary, AB Canada.

ReCeIved February 12, 2003. AcCePTedinfinalform November 27, 2003. Reprint requests to: Luanne Metz, Department of Clinical Neurosciences, Foothills Medical Centre, Multiple Sclerosis Clinic, Main Floor SSB, 1403-29th Street NW, Calgary, AB, T2N 2T9 Canada. 
hemiparesis, bilateral extensor plantar reflexes, asymmetric hyperreflexia, and incoordination of both hands.

An MRI showed several T2 hyperintense lesions in the white matter including: two lesions adjacent to the left frontal horn of the lateral ventricle (dorsolateral inferior frontal lobe), two lesions within the corpus callosum, and one in the left parietal lobe. This episode recovered following treatment with high dose methylprednisolone.

Speech pathology assessment following recovery revealed both speech and language to be normal. Repeat assessment during an episode of 'foreign accent' revealed speech accent characteristics consistent with those found in previous studies..$^{2,3,6-8}$ She had dysprosody, anomalous phonetic features, and speech sound errors. There was failure to reduce unstressed syllables to a schwa that resulted in equal and excess stress on syllables and prolongations of vowels. There was the addition of schwa ("uh") to the ends of some words. Vowel tensing of many lax vowels occurred, consistent with a tense vocal tract setting and the patient's report of a tense jaw. Consonant distortions and substitutions including /r/ rounding, flaps pronounced as stops, and "th" a fricative pronounced as /t/ a stop occurred. Language was intact except for the presence of minor grammatical errors and there was no dysarthria or apraxia.

\section{DISCUSSION}

Previous studies suggest the concept of a generic foreign accent. Blumstein et $\mathrm{al}^{8}$ in 1987 report, "the normal listener categorizes this speech pattern as a generic foreign accent because the anomalous speech characteristics while not part of the English phonetic inventory, reflect stereotypical features which are a part of the universal phonetic properties found in natural language". Aronson ${ }^{2}$ in 1985 described 25 cases from 1907 to 1978 and found that $68 \%$ had associated aphasia, apraxia or dysarthria with the majority having speech patterns that most closely resembled apraxia of speech.

The lesion identified by imaging or autopsy in those with foreign accent syndrome varies, however, most of the reported cases involve part of the dominant inferior dorsolateral premotor cortical-striatal-pallidal-thalamic circuit which mediates motor speech planning. ${ }^{2-5,7-9}$ This is consistent with the study by
Moonis in which a patient with a mild concussion developed a foreign accent syndrome. That patient showed no defects on an unenhanced MRI scan but on SPECT scan showed a focal hypoperfused area in the left inferior dorsolateral frontal lobe and left caudate nucleus. ${ }^{3}$

Our patient's episodes of foreign accent are thought to be caused by her MS because of their fluctuating nature, their association with other fluctuating neurological complaints, their worsening with fatigue and their response to high dose steroid treatment. This patient has been on glatiramir acetate and relapse free for the past three years.

\section{REFERENCES}

1. Pick A. Uber anerungen des sprach-characters als begleiterscheinung aphasischer strorungen. Zeitschrift fuer de gesamte Neurun Psychologie 1919;54:230-241.

2. Aronson AE. Clinical Voice Disorders. New York: Thieme Inc. 1985:119-123.

3. Moonis M, Swearer JM, Blumstein SE, et al. Foreign accent syndrome following a closed head injury: perfusion deficit on single photon emission tomography with normal magnetic resonance imaging. Neuropsychiatr Neurophysiol Behav Neurol 1996; 9:272-279.

4. Roth EJ, Fink K, Cherney LR, Hall KD. Reversion to a previously learned foreign accent after stroke. Arch Phys Med Rehabil 1997;78:550-552.

5. Takayama Y, Sugishita M, Kido T, Ogawa M, Akiguchi I. A case of foreign accent syndrome without aphasia caused by a lesion of the left precentral gyrus. Neurology 1993;43:1361-1363.

6. Kurowski KM, Blumstein SE, Alexander M. The foreign accent syndrome: a reconsideration. Brain Lang 1996; 54 (1): 1-25.

7. Gurd JM, Bessell NJ, Bladon RA, Bamford JM. A case of foreign accent syndrome, with follow-up clinical, neuropsychological and phonetic descriptions. Neuropsychologia 1988; 26(2): 237251.

8. Blumstein SE, Alexander MP, Ryalls JH, KatzW, Dworetzky B. On the nature of the foreign accent syndrome: a case study. Brain Lang 1987; 31(2): 215-244.

9. Graff-Radford NR, Cooper WE, Colsher PL, Damasio AR. An unlearned foreign "accent" in a patient with aphasia. Brain Lang 1986;28:86-94.

10. Monrad-Krohn GH. Dysprosody or altered "melody of language." Brain 1947;70:405-415. 